\title{
Hypertrophic cardiomyopathy in the elderly
}

Hypertrophic cardiomyopathy, defined as idiopathic hypertrophy of a non-dilated ventricle, has a range of morphological and clinical features and can occur from infancy to old age. ${ }^{1}$ Hypertrophic cardiomyopathy, although initially regarded as a rare disorder of young patients with symptoms, is probably not uncommon. In the early years, after the first descriptions of the disease, most clinical studies came from a few tertiary referral centres ${ }^{2}-$ this biased selection towards young patients with symptoms who had a disease characterised by asymmetrical septal hypertrophy and dynamic left ventricular outflow tract obstruction. ${ }^{3-5}$ Since then, however, it has become apparent, particularly with the widespread application of echocardiography, that hypertrophic cardiomyopathy occurs in patients of all ages with or without regional septal hypertrophy, an outflow tract gradient, or symptoms. ${ }^{6-12}$

\section{Diagnosis}

Echocardiography is now the technique of choice for the diagnosis and assessment of hypertrophic cardiomyopathy. The echocardiogram usually shows hypertrophy of the ventricular septum, but any region of the left ventricle (and occasionally the right ventricle) can be affected. Left ventricular contraction is hyperdynamic and there is often impaired and incoordinate relaxation and a reduced rate of filling. ${ }^{13-16}$ These features are similar in all age groups, but in the elderly fibrous thickening of the ventricular septum in the area of mitral septal contact may be prominent and there can be quite extensive mitral annular calcification. ${ }^{17}$ The aortic valve may also be calcified and regurgitant.

In a young patient, the echocardiographic finding of idiopathic left ventricular hypertrophy may lead with certainty to the diagnosis of hypertrophic cardiomyopathy; but in the elderly there are more frequent secondary causes of left ventricular hypertrophy. In particular, increasing age is clearly associated with increased left ventricular mass and septal thickness and changes in diastolic function. ${ }^{18-22}$ In extreme old age, the septum may not only be hypertrophied but also sigmoid, which can also simulate the appearance of hypertrophic cardiomyopathy. ${ }^{23}$ In children with clinical evidence or a family history of hypertrophic cardiomyopathy rapid development of left ventricular hypertrophy can be seen by echocardiography over four years. Increases in wall thickness of up to $23 \mathrm{~mm}$ have been noted. ${ }^{24}$ In contrast, a similar study in 65 adults showed that none demonstrated an increase in left ventricular wall thickness and $14 \%$ had a significant reduction with relative enlargement of the left ventricular cavity. ${ }^{25}$ In addition, echocardiographic measurements of left ventricular mass and maximum wall thickness were significantly higher in patients aged 21-30 than in older patients. Younger patients also had the most severe and diffuse hypertrophy in a study of 700 individuals with hypertrophic cardiomyopathy. ${ }^{26}$ However, some patients, particularly women, may present in their sixth or seventh decade after a prolonged asymptomatic (latent?) period with progressive symptoms and often a poor response to medical treatment.
Such patients may have a distinctive type of the disease, with modest septal hypertrophy, distortion of the left ventricular outflow tract, and a gradient generated by the posterior motion of the septum against the restricted movement of a calcified mitral valve. ${ }^{17}$

\section{Prognosis}

While premature sudden death is a well-known feature of hypertrophic cardiomyopathy it is relatively uncommon in patients with hypertrophic cardiomyopathy. ${ }^{27}{ }^{28}$ Sudden death is not confined to the young but most studies of the natural course of the disease have emphasised its rarity in elderly patients. ${ }^{29}{ }^{30} \mathrm{~A}$ retrospective analysis of 284 patients showed that sudden death was more common in those aged $<14$ years and in older patients with symptoms. The annual mortality for cases diagnosed in childhood was $5.9^{\circ}$ o compared with $2.5 \%$ for cases in adults. ${ }^{31}$ The better prognosis of elderly patients may reflect the survival of a subset of patients at low risk of sudden death, especially those with ventricular tachycardia or an adverse family history. ${ }^{32}{ }^{33}$ Lack of exertion in the elderly may also have a protective effect.

\section{Hypertensive hypertrophic cardiomyopathy?}

In 1957, when Brock first described an elderly patient with severe left ventricular hypertrophy and an outflow tract gradient, he concluded that the disease was secondary to hypertension ${ }^{34}$; this was not borne out in subsequent reports. ${ }^{35}$ Though the morphological and echocardiographic features of hypertrophic cardiomyopathy and severe secondary left ventricular hypertrophy are usually distinctive ${ }^{37}$ diagnosis is complicated in mildly hypertensive patients with unequivocal echocardiographic features of hypertrophic cardiomyopathy in whom the degree of hypertrophy is inappropriate for the severity of hypertension. This problem was emphasised by the identification of 21 , mostly elderly, female patients with severe concentric hypertrophy and small left ventricular cavity with hyperdynamic left ventricular contraction and abnormal diastolic function. ${ }^{38}$ These patients usually presented in heart failure and their symptoms tended to be relieved by $\beta$ blockade or calcium channel blocking drugs, rather than the traditional treatment of heart failure. This condition (hypertensive hypertrophic cardiomyopathy) suggests the coexistence of hypertrophic cardiomyopathy and hypertension. Among patients with hypertrophic cardiomyopathy those with hypertension tend to be older than those without. The clinical and echocardiographic features of hypertrophic cardiomyopathy were indistinguishable in those with hypertension and those without, except that hypertensive patients had thicker ventricular walls. ${ }^{390}$ The wide variability of expression of hypertrophic cardiomyopathy implies that other stimuli to the expression of hypertrophy such as pressure overload and neurohormonal factors may be important in genetically susceptible individuals. Further careful clinical and genetic 
studies are required to clarify whether the definition of hypertrophic cardiomyopathy needs to be enlarged to include hypertension or whether hypertensive hypertrophic cardiomyopathy is a distinct clinical entity.

\section{Treatment}

Patients of all ages without symptoms or arrhythmias do not require treatment. Dyspnoea or anginà are often adequately managed with $\beta$ blockade or calcium antagonis$\mathrm{ts}^{41}{ }^{42}$ and amiodarone improves prognosis in patients with arrhythmias. ${ }^{43}$ Surgery should not be excluded in the elderly because the results of myotomy and myectomy in those with outflow tract gradients (with or without concomitant coronary bypass grafting) are good. ${ }^{44} 45$

The presentation of an apparently congenital disorder in the elderly (without previous heart disease) is puzzling. While the elderly may present with typical symptoms of dizziness, syncope, breathlessness, chest pain, and palpitation the diagnosis is often delayed because these symptoms can be caused by coexisting disease. In addition, elderly patients can present in intractable heart failure caused by abnormalities of left ventricular relaxation and filling, and the diagnosis may be obscured by mitral regurgitation and mitral annular calcification. Although the distinctions between primary and secondary causes of hypertrophy are clear in young adults they are vague in the very young and the elderly. However, identification of the cause of hypertrophy probably has little influence on management.

LEONARD M SHAPIRO

Regional Cardiac Unit

Papworth Hospital,

Papworth Everard,

Cambridge CB3 $8 R E$

1 Goodwin JF. The frontiers of cardiomyopathy. Br Heart J 1982;48:1-18.

2 Spirito P, Chiarella F, Caratinol L, et al. Clinical course and prognosis of hypertrophic cardiomyopathy in an out-patient population. N Engl J Med 1989;320:749-55.

3 Henry WL, Clark CE, Griffith JM, et al. Mechanism of left ventricular outflow obstruction in patients with obstructive asymmetric septal hypertrophy (idiopathic hypertrophic sub-aortic stenosis). Am J Cardiol 1975;35:377-45.

4 Henry WL, Clark CE, Epstein SE. Asymmetric septal hypertrophy (ASH): echocardiographic identification of the pathognomonic anatomic abnormality of IHSS. Circulation 1973;47:225-33.

5 Braunwald E, Lambrew CT, Rockoff SD, Ross J Jr, Morrow AG. Idiopathic hypertrophic subaortic stenosis: a description of the disease based upon an analysis of 64 patients. Circulation 1964;30(suppl IV):IV-3-64.

6 Maron BJ, Henry WL, Clark CE, Redwood DR, Roberts WC, Epstein SE. Asymmetric septal hypertrophy in childhood. Circulation 1976;53:9-19.

7 Fiddler GI, Tajik AJ, Weidman WH, McGoon DC, Ritter DG, Giuliani ER. Idiopathic hypertrophic subaortic stenosis in the young. Am J Cardiol 1978;42:793-9.

8 Krasnow N, Stein R. Hypertrophic cardiomyopathy in the aged. Am Heart J 1978;96:326-36.

9 Whiting RB, Powell WJ, Dinsmore RE, Saunders CA. Idiopathic hypertrophic sub-aortic stenosis in the elderly. N Engl J Med 1971;285:196-200.

10 Petrin TJ, Tavel ME. Idiopathic hypertrophic sub-aortic stenosis as observed in a large community hospital: relation to age and history of hypertension. J Am Geriatr Soc 1979;27:43-6.

11 Maron BJ, Gottdiener JS, Epstein SE. Patterns and significance of the distribution of left ventricular hypertrophy in hypertrophic cardistribution of left ventricular hypertrophy in hypertrophic car-
diomyopathy: a wide-angle two-dimensional study of 125 patients. $\mathrm{Am} \mathrm{J}$ diomyopathy: a wide-ang

12 Shapiro LM, McKenna WJ. Distribution of left ventricular hypertrophy in hypertrophic cardiomyopathy: a two-dimensional echocardiographic study. J Am Coll Cardiol 1983;2:437-44.

13 Sanderson JE, Traill TA, St John Sutton MG, Brown DJ, Gibson DG, Goodwin JF. Left ventricular relaxation and filling in hypertrophic cardiomyopathy: an echocardiographic study. $B r$ Heart J 1978;40: 596-601.

14 Gibson DG, Traill TA, Hall RJC, Brown DJ. Echocardiographic features of secondary left ventricular hypertrophy. Br Heart J 1979;41:54-9.

15 St John Sutton MG, Tajik AJ, Gibson DG, et al. Echocardiographic assessment of left ventricular filling and septal and posterior wall dynamics in idiopathic hypertrophic sub-aortic stenosis. Circulation 1978;57: 512-20.

16 Maron BJ, Spirito P, Green KJ, Wesley YE, Bonow RO, Arce J. Noninvasive assessment of left ventricular diastolic function by pulsed Doppler echocardiography in patients with hypertrophic cardiomyopathy. J Am Coll Cardiol 1987;10:733-42.

17 Lewis JF, Maron BJ. Elderly patients with hypertrophic cardiomyopathy: a subset with distinctive left ventricular morphology and progressive subset with distinctive left ventricular morphology and
clinical course late in life. $J$ Am Coll Cardiol 1989;13:36-45.

18 Savage DD, Abbott RD, Padgett S, Anderson SJ, Garrison RJ. Epidemiological features of left ventricular hypertrophy in normotensive and hypertensive subjects. In: Terkeurs HEDJ, Schipperheyn JJ, eds. Cardiac left ventricular hypertrophy. Amsterdam: Martinus Nijholt, 1983:1-16.

19 Gerstenblith G, Frederiksen J, Y in FCP, Fortuin NJ, Lakatta EG, Weisfeldt $\mathrm{T}$. Echocardiographic assessment of a normal adult aging population. Circulation 1977;56:273-8.

20 Gardin JM, Henry WL, Savage DD, Epstein SE. Echocardiographic evaluation of an older population without clinically apparent heart disease. Am J Cardiol 1977;39:277-9.

21 Marcomichelakis J, Withers R, Newman GB, O'Brien K, Emmanuel R. The relation of age to the thickness of the interventricular septum, the posterior left ventricular wall and their ratio. Int $J$ Cardiol 1983;4:405-15.

22 Miyatake $\mathrm{K}$, Okamato $\mathrm{M}$, Kinoshita $\mathrm{N}$, et al. Augmentation of atrial contribution to left ventricular inflow with aging assessed by intracardiac contribution to left ventricular inflow with aging a
Doppler flowmetry. Am J Cardiol 1984;53:586-9.

23 Waller BF, Roberts WC. Cardiovascular disease in the very elderly. Am J Cardiol 1984;54:231-3.

24 Maron BJ, Spirito P, Wesley Y, Arce J. Development and progression of left ventricular hypertrophy in children with hypertrophic cardiomyopathy. N Engl J Med 1986;315:610-4.

25 Spirito P, Maron BJ. Absence of progression of left ventricular hypertrophy in adult patients with hypertrophic cardiomyopathy. J Am Coll Cardiol 1987;9:1013-7

26 Spirito P, Maron BJ. Relation between extent of left ventricular hypertrophy and age in hypertrophic cardiomyopathy. J Am Coll Cardiol 1989;13: $820-3$.

27 Frank S, Braunwald E. Idiopathic hypertrophic sub-aortic stenosis: clinical analysis of 126 patients with emphasis on the natural history. Circulation 1968;37:759-88.

28 Hardarson T, De la Calzada CS, Curiel R, Goodwin JF. Prognosis and mortality of hypertrophic obstructive cardiomyopathy. Lancet 1973;ii: 1462-7.

29 Shah PM, Adelman AG, Wigle ED, et al. The natural (and unnatural) history of hypertrophic obstructive cardiomyopathy. Circ Res 1973;34 and 35(suppl II):II-179-95.

30 Nicod P, Polikar R, Peterson KL. Hypertrophic cardiomyopathy and sudden death. N Engl J Med 1988;318:1255-7.

31 McKenna WJ, Deanfield J; Farugui A, et al. Prognosis in hypertrophic cardiomyopathy: role of age and clinical, electrocardiographic and hemodynamic features. Am J Cardiol 1981;47:532-8.

32 McKenna WJ, England D, Doi YL, Deanfield JE, Oakley C, Goodwin JF. Arrhythmias in hypertrophic cardiomyopathy. I: Influence on prognosis. Br Heart J 1981;46:168-72.

33 Maron BJ, Lipson LC, Roberts WC, Savage DD, Epstein SE. "Malignant" hypertrophic cardiomyopathy: identification of a sub-group of families
with unusually frequent premature death. Am J Cardiol 1978;41:1133-40.

34 Brock R. Functional obstruction of the left ventricle (acquired aortic subvalvular stenosis). Guy's Hosp Rep 1957;106:221-38.

35 Brock R. Functional obstruction of the left ventricle (acquired aortic subvalvular stenosis). Guy's Hosp Rep 1959;109:126-43.

36 Teare D. Asymmetrical hypertrophy of the heart in young adults. Br Heart J 1958;20:1-8.

37 Shapira LM, Keinbenne A, McKenna WJ. The distribution of left ventricular hypertrophy in hypertrophic cardiomyopathy; comparison to athletes and hypertensives. Eur Heart J 1985;6:967-74.

38 Topol EJ, Traill TA, Fortuin N. Hypertensive hypertrophic cardiomyopathy in the elderly. $N$ Engl $J$ Med 1985;312:277-83.

39 Pearson AC, Gudipati CV, Labovitz AJ. Systolic and diastolic flow abnormalities in elderly patients with hypertensive hypertrophic cardiomyopathy. J Am Coll Cardiol 1988;12:989-95.

40 Karma R, Lever HM, Healy BP. Hypertensive hypertrophic cardiomyopathy or hypertrophic cardiomyopathy with hypertension? A study of 78 patients. J Am Coll Cardiol 1989;13:580-4.

41 Frank MJ, Abdulla AM, Watkins LO, et al. Long-term medical management of hypertrophic cardiomyopathy; usefulness of propranolol. Eur Heart $J$ of hypertrophic cardiomyop
$1983 ; 4$ (suppl F):155-64.

42 Chatterjee $\mathrm{K}$. Calcium antagonist agents in hypertrophic cardiomyopathy. Am J Cardiol 1987;59:146-9B.

43 McKenna WJ, Oakley CM, Krikler DM, Goodwin JF. Improved survival with amiodarone in patients with hypertrophic cardiomyopathy and ventricular tachycardia. Br Heart $J$ 1985;53:412-6.

44 Koch HP, Maron BJ, Epstein SE, Morrow AG. Results of operation for obstructive hypertrophic cardiomyopathy in the elderly. Am J Cardiol 1980;46:963-7.

45 Siegman IL, Maron BJ, Permut LC McIntosh CL, Clark RE. Results of operation for co-existent obstructive hypertrophic cardiomyopathy and coronary artery disease. J Am Coll Cardiol 1989;13:1527-33. 